\title{
Dysplasia in Barrett Esophagus
}

\section{Implications for Chemoprevention}

\author{
Christopher D. Lao, M.D., M.P.H. ${ }^{1}$ \\ Melanie Simmons, B.S. ${ }^{1}$ \\ Sapna Syngal, M.D., M.P.H. ${ }^{2}$ \\ Robert S. Bresalier, M.D. ${ }^{3}$ \\ Laurie Fortlage, M.S., R.D. ${ }^{1}$ \\ Daniel Normolle, Ph.D. ${ }^{4}$ \\ Kent A. Griffith, M.S., M.P.H. ${ }^{5}$ \\ Henry D. Appelman, M.D. ${ }^{6}$ \\ Dean E. Brenner, M.D. ${ }^{1,7}$ \\ ${ }^{1}$ Department of Internal Medicine, University of \\ Michigan Medical Center, Ann Arbor, Michigan. \\ ${ }^{2}$ Dana-Farber/Brigham and Women's Cancer Cen- \\ ter, Boston, Massachusetts. \\ ${ }^{3}$ Division of Gastroenterology, Henry Ford Medical \\ Center, Detroit, Michigan. \\ ${ }^{4}$ Department of Radiation Oncology, University of \\ Michigan Medical Center, Ann Arbor, Michigan. \\ ${ }^{5}$ Department of Biostatistics, University of Michi- \\ gan Medical Center, Ann Arbor, Michigan. \\ ${ }^{6}$ Department of Pathology, University of Michigan \\ Medical Center, Ann Arbor, Michigan. \\ ${ }^{7}$ Department of Pharmacology, University of Mich- \\ igan Medical Center, Ann Arbor, Michigan.
}

Supported by Grant CN-65000 from the National Cancer Institute; Grant M01-RR000042 from the Clinical Research Center, University of Michigan Medical Center; and the Department of Veterans Affairs, Ann Arbor Veterans Affairs Medical Center.

Robert Bresalier's current address: Department of Gastrointestinal Medicine and Nutrition, The University of Texas M. D. Anderson Cancer Center, Houston, Texas.

Address for reprints: Dean E. Brenner, M.D., 2150 Cancer Center and Geriatrics Center, University of Michigan Medical Center, Ann Arbor, Ml 48109-0930; Fax: (734) 647-9817; E-mail: dbrenner@umich.edu

Received September 22, 2003; revision received December 24, 2003; accepted January 22, 2004.
BACKGROUND. Dysplasia in Barrett esophagus is a premalignant condition that is associated with an increased risk of developing esophageal adenocarcinoma. Unfortunately, clinical investigation aimed at prevention of progression to malignant disease has been hampered by the variable prevalence of dysplasia reported in the literature. The objective of the current study was to more accurately determine the prevalence of dysplasia among individuals with Barrett esophagus who would be available for enrollment in a chemoprevention trial.

METHODS. The pathology archives of 3 institutions were reviewed over a 5-year period for all reports of diagnoses of Barrett esophagus. Surgical cases, malignancies, and duplicate or referral cases were excluded from the analysis.

RESULTS. A total of 790 cases of Barrett esophagus were identified. Of these, 37 (4.7\%) were cases of low-grade dysplasia (LGD), and 20 (2.5\%) were cases of high-grade dysplasia. The University of Michigan Medical Center (Ann Arbor, MI) diagnosed 18 cases of LGD, Henry Ford Hospital (Detroit, MI) diagnosed 15 cases of LGD, and Brigham and Women's Hospital (Boston, MA) diagnosed 4 cases of LGD in patients with Barrett esophagus over the 5-year study period.

CONCLUSIONS. The confirmed low prevalence of cases of LGD will affect the design of future clinical trials of chemopreventive interventions for Barrett esophagus. Cancer 2004;100:1622-7. (C) 2004 American Cancer Society.

KEYWORDS: dysplasia, Barrett esophagus, chemoprevention, esophageal adenocarcinoma.

n patients with Barrett esophagus or Barrett mucosa, metaplastic columnar epithelium replaces the normal squamous epithelium in the distal esophagus. This condition develops in approximately 10$15 \%$ of patients with chronic gastroesophageal reflux. ${ }^{1,2}$ Barrett esophagus is the major recognized risk factor for esophageal adenocarcinoma, and patients have a 30-40-fold increased risk of developing malignant disease compared with the general population. ${ }^{3,4}$

The incidence of adenocarcinoma of the esophagus has been increasing steadily in the United States for the last 20 years, with the incidence in white males growing by $>350 \%$ over that time period. ${ }^{5}$ Aggressive medical management of acid reflux, lifestyle modifications, laser ablation, and endoscopic surveillance have been recommended for many patients with Barrett esophagus. ${ }^{6-8}$ Whether these interventions are cost-effective or reduce mortality from esophageal cancer remains controversial. ${ }^{9}$

Dysplasia in Barrett esophagus is an intraepithelial neoplasia and the primary predictor of progression to adenocarcinoma. ${ }^{10}$ Highgrade dysplasia (HGD) in Barrett esophagus frequently undergoes malignant transformation and is associated with a high rate of occult malignancy. For this reason, many patients with HGD undergo 
esophageal resection. ${ }^{11,12}$ Limited data are available for elucidating the rate at which low-grade dysplasia (LGD) progresses to HGD or carcinoma. Some studies suggest that the rate ranges from $10 \%$ to $30 \%$ over 5 years. ${ }^{13-16}$

Due to the increased risk of malignant disease and the lack of good treatment options for LGD in Barrett esophagus, a randomized chemoprevention trial was recently performed in which difluoromethylornithine (DFMO) was given to individuals with Barrett esophagus who either had LGD or did not exhibit dysplasia. ${ }^{17}$ In that study, in which a single pathologist reviewed every case, the number of patients identified and enrolled was exceedingly small (LGD: $n=2$; negative for dysplasia: $n=77$ ). This finding was unexpected, as the prevalence of dysplasia reported in the literature is highly variable. ${ }^{13,18-25}$ One study reported LGD in as many as $70.8 \%$ of patients with Barrett esophagus. ${ }^{18}$ This variability in prevalence rates represents a challenge in designing and implementing randomized chemoprevention studies. In the current study, we searched within a small multiinstitutional consortium to retrospectively identify individuals with dysplasia in Barrett esophagus who would be available for enrollment in a chemoprevention trial.

\section{MATERIALS AND METHODS}

\section{Study Design and Population}

A retrospective review of the pathology archives of the University of Michigan (Ann Arbor, MI), Henry Ford Hospital (Detroit, MI), and Brigham and Women's Hospital (Boston, MA) over a 5-year period was performed to identify all cases of Barrett esophagus. Reports of specimens that were obtained from biopsies and resections above the gastroesophageal junction and reported as either intestinal-type Barrett esophagus, specialized-type Barrett esophagus, or specialized-type columnar epithelium were included in the analysis. No pathology specimens or slides were pulled for review.

After obtaining institutional review board exemption, pathology reports from the University of Michigan over the period 1995-1999 were reviewed for eligibility. Original identifiers for patients were used initially to identify duplicate reports. Case numbers were subsequently assigned, and all identifiers were then removed. If there were duplicate reports for any one case, then the most advanced diagnosis was used. When there were multiple reports with the same diagnosis, the earliest diagnosis was used. The data recorded from each report included the type of Barrett esophagus (negative for dysplasia, indefinite for dysplasia, LGD, and HGD), age, gender, whether the specimen was obtained after a biopsy or a resection, and the year of the report. Additional information included the pathologist to whom the case was referred, the physician who wrote the official report, the five-digit accession number, and the hospital registration number. Reports with any findings of cancer, surgically resected cases, and referral cases were removed before analysis.

Data from Henry Ford Hospital included the period between 1996 and the first 3 months of 2000. Data from Brigham and Women's Hospital were collected for the period 1995-1999. Data were collected and handled at both institutions in the same manner as at the University of Michigan.

Cases of Barrett esophagus were summarized by degree of dysplasia, institution of origin, and year of diagnosis. Differences among institutions in the proportion of cases by degree of dysplasia were tested using the standard Pearson chi-square statistic. Comparisons of case characteristics between types of dysplasia were made using the two-sample $t$ test and the chi-square statistic when appropriate. Two-sided $P$ values $<0.05$ were considered to be statistically significant.

\section{Definition of Outcome}

Barrett esophagus was diagnosed if metaplastic columnar epithelium was observed in biopsy specimens obtained from the tubular esophagus above the gastroesophageal junction. Dysplasia was defined as neoplastic epithelium that was not invasive. Cytologic changes included nuclear enlargement, hyperchromatism, pleomorphism and stratification, atypical-appearing mitoses, and loss of cytoplasmic maturation. Architectural changes included crowding of tubules and/or villiform surfaces. ${ }^{26}$ LGD was characterized by these changes occurring with a relatively low level of intensity and by more closely caricatured nonneoplastic epithelium, whereas HGD was characterized by more intense changes. If the biopsy specimen had morphologic changes that were not clearly dysplastic but also not clearly reactive, then the biopsy specimen was considered to be indefinite for dysplasia.

\section{RESULTS}

Among the 3 institutions involved in the study, 790 cases of Barrett esophagus met the study criteria. Case characteristics are shown in Table 1. Seventy percent of the cases who were negative for dysplasia were male, and $30 \%$ were female. Males accounted for $78 \%$ of LGD cases and $90 \%$ of HGD cases. The mean age of cases who were negative for dysplasia was $57.8 \pm 13.8$ years, the mean age of cases with LGD was $62.9 \pm 12.7$ years, and the mean age of cases with HGD was 67.3 \pm 12.8 years. The mean age of cases with HGD was 
TABLE 1

Baseline Characteristics of Cases of Dysplasia in Barrett Esophagus

\begin{tabular}{|c|c|c|c|c|c|}
\hline Characteristic & $\begin{array}{l}\text { Negative } \\
\text { No. (\%) }\end{array}$ & $\begin{array}{l}\text { Indefinite } \\
\text { No. (\%) }\end{array}$ & $\begin{array}{l}\text { Low-grade dysplasia } \\
\text { No. (\%) }\end{array}$ & $\begin{array}{l}\text { High-grade dysplasia } \\
\text { No. (\%) }\end{array}$ & $\begin{array}{l}\text { Total } \\
\text { No. }(\%)\end{array}$ \\
\hline \multicolumn{6}{|l|}{ Gender } \\
\hline Male & 476 (69) & $28(60)$ & $29(78)$ & $18(90)$ & $551(70)$ \\
\hline Female & $210(31)$ & $19(40)$ & $8(22)$ & $2(10)$ & $239(30)$ \\
\hline $\mathrm{Age}^{\mathrm{a}}$ & $57.8 \pm 13.8$ & $62.2 \pm 11.4$ & $62.9 \pm 12.7$ & $67.3 \pm 12.8^{b}$ & \\
\hline
\end{tabular}

TABLE 2

Frequency of Dysplasia in Barrett Esophagus by Institution over the Study Period

\begin{tabular}{lllll}
\hline & $\begin{array}{l}\text { Henry Ford } \\
\text { Hospital }^{\mathbf{a}}\end{array}$ & $\begin{array}{l}\text { University of Michigan } \\
\text { Medical Center }\end{array}$ & $\begin{array}{l}\text { Brigham and Women's } \\
\text { Hospital }\end{array}$ & Total \\
\cline { 2 - 4 } Pathology & No. (\%) & No. (\%) & No. (\%) & No. (\%) \\
\hline Dysplasia & & & \\
Negative & $163(85.3)$ & $303(84.2)$ & $220(92.3)$ & $686(86.8)$ \\
Indefinite & $11(5.8)$ & $27(7.5)$ & $9(3.8)$ & $47(5.9)$ \\
Low-grade & $15(7.9)^{\mathbf{b}}$ & $18(5.0)$ & $4(1.7)$ & $37(4.7)$ \\
High-grade & $2(1.0)$ & $12(3.3)$ & $6(2.5)$ & $20(2.5)$ \\
Total & 191 & 360 & 239 & 790 \\
\hline a Includes data covering a period of 4 years and 3 months. & & \\
b $P=0.004$ for comparison with low-grade dysplasia group at Brigham and Women's Hospital. & & \\
\hline
\end{tabular}

statistically different from the mean age of cases who were negative for dysplasia $(P=0.004)$.

Of the 790 cases identified, 360 were from the University of Michigan, 191 were from Henry Ford Hospital, and 239 were from Brigham and Women's Hospital (Table 2). When all institutions were combined, negative for dysplasia accounted for 686 cases, indefinite for dysplasia accounted for 47 cases, LGD accounted for 37 cases, and HGD accounted for 20 cases. At the University of Michigan, Henry Ford Hospital, and Brigham and Women's Hospital, LGD represented $5.0 \%, 7.9 \%$, and $1.7 \%$ of all Barrett esophagus cases, respectively. The difference between Henry Ford Hospital and Brigham and Women's Hospital was statistically significant $(P=0.004)$. None of the rates for other dysplasia types were statistically different across institutions.

Table 3 shows the distribution of the types of Barrett esophagus by year. For all institutions, the number of cases that were negative for dysplasia ranged from 118 to 174 per year, the number of cases that were indefinite for dysplasia ranged from 8 to 11 per year, the number of LGD cases ranged from 5 to 12 per year, and the number of HGD cases ranged from 2 to 6 per year.
TABLE 3

Number of Cases of Barrett Esophagus (All Institutions) by Year of Collection

\begin{tabular}{llllll}
\hline Pathology & Yr 1 & Yr 2 & Yr 3 & Yr 4 & Yr 5 \\
\hline Dysplasia & & & & & \\
Negative & 136 & 118 & 136 & 174 & 122 \\
Indefinite & 9 & 11 & 8 & 11 & 8 \\
Low-grade & 5 & 10 & 5 & 12 & 5 \\
High-grade & 2 & 3 & 3 & 6 & 6 \\
Total & 152 & 142 & 152 & 203 & 141 \\
\hline
\end{tabular}

${ }^{\text {a }}$ Data from Henry Ford Hospital covers only the first 3 months of the year.

\section{DISCUSSION}

The current multiinstitutional review supports the finding that few individuals with dysplasia in Barrett esophagus are available for enrollment in chemoprevention trials. ${ }^{17}$ Dysplasia in Barrett esophagus is a premalignant condition that has been the focus of attention for esophageal adenocarcinoma prevention strategies and remains the primary predictor of malignant progression. ${ }^{10}$ However, the limited number of individuals with LGD has ramifications for those committed to the clinical study of Barrett esophagus.

Variable rates of dysplasia in the literature have 
TABLE 4

Long-Term Series of Low-Grade Dysplasia in Barrett Esophagus without Concurrent Malignancy

\begin{tabular}{|c|c|c|c|c|c|c|}
\hline Study & Type & Study period & $\begin{array}{l}\text { Pathology } \\
\text { review }^{\mathrm{a}}\end{array}$ & $\begin{array}{l}\text { No. of } \\
\text { BE cases }\end{array}$ & $\begin{array}{l}\text { No. of LGD } \\
\text { cases }(\%)\end{array}$ & Comments \\
\hline Hameeteman et al., $1989^{13}$ & $\begin{array}{l}\text { Single-institution, } \\
\text { prospective }\end{array}$ & Unknown $\left(14 \mathrm{yrs}^{\mathrm{c}}\right)$ & Yes & 50 & $9(18.0)$ & $\begin{array}{l}\text { Combined percentage of } \\
\text { indefinite and LGD cases: } \\
28.0 \%\end{array}$ \\
\hline Miros et al., $1991^{24}$ & $\begin{array}{l}\text { Single-institution, } \\
\text { prospective }\end{array}$ & 1981-1988 & No & 81 & $21(25.9)$ & $\begin{array}{l}\text { Indefinite and LGD cases } \\
\text { combined }\end{array}$ \\
\hline Weston et al., $1997^{20}$ & $\begin{array}{l}\text { Single-institution, } \\
\text { prospective }\end{array}$ & Unknown $\left(40\right.$ mos $\left.^{\mathrm{d}}\right)$ & Yes & 152 & $16(10.5)$ & $\begin{array}{l}\text { Nine of } 16 \text { LGD cases not } \\
\text { confirmed on follow-up; } \\
20 \% \text { incident cases on } \\
\text { small subset }\end{array}$ \\
\hline O'Connor et al., $1999^{21}$ & $\begin{array}{l}\text { Single-institution, } \\
\text { retrospective }\end{array}$ & 1979-1995 & No & 136 & $34(25.0)$ & $\begin{array}{l}\text { Twenty-five LGD cases (73\%) } \\
\text { not confirmed on follow-up }\end{array}$ \\
\hline Hirota et al., $1999^{19}$ & $\begin{array}{l}\text { Single-institution, } \\
\text { prospective }\end{array}$ & 1995-1996 & Yes & 63 & $5(7.9)$ & Incident cases not reported \\
\hline Reid et al., $2000^{25}$ & $\begin{array}{l}\text { Single-institution, } \\
\text { prospective }\end{array}$ & 1983-1998 & No & 327 & $43(13.1)$ & Incident cases not reported \\
\hline Schnell et al., $2001^{18}$ & $\begin{array}{l}\text { Single-institution, } \\
\text { retrospective }\end{array}$ & 1979-2000 & No & 1057 & 748 (70.8) & \\
\hline Gopal et al., $2003^{22}$ & $\begin{array}{l}\text { Multiinstitutional, } \\
\text { prospective }\end{array}$ & 1994-1998 & No & 304 & $29(9.5)$ & $\begin{array}{l}\text { Seventy-five percent of cases } \\
\text { from Veterans } \\
\text { Administration hospitals }\end{array}$ \\
\hline Conio et al., $2003^{23}$ & $\begin{array}{l}\text { Multiinstitutional, } \\
\text { prospective }\end{array}$ & 1987-1997 & Yes & 166 & $40(24.1)$ & $\begin{array}{l}\text { Thirty LGD cases }(75 \%) \text { not } \\
\text { confirmed on follow-up }\end{array}$ \\
\hline $\begin{array}{l}\text { BE: Barrett esophagus; LGD: low- } \\
\text { a Denotes whether pathology was } \\
\text { bercestage of patients who ever } \\
{ }^{b} \text { Percenta } \\
\text { c Longest duration of follow-up; } \\
\text { d Duration of study period; dates }\end{array}$ & $\begin{array}{l}\text { dysplasia. } \\
\text { ed as reviewed and/or c } \\
\text { ndings of LGD in Barret } \\
\text { surveillance not specifi } \\
\text { reillance not specified. }\end{array}$ & $\begin{array}{l}\text { ed by an additional patholc } \\
\text { agus during the specified } t\end{array}$ & & & & \\
\hline
\end{tabular}

made the design of clinical chemoprevention trials challenging (Table 4). ${ }^{13,18-25}$ Several single-institution studies have attempted to directly measure the prevalence and/or incidence of dysplasia in Barrett esophagus. ${ }^{19-21,24}$ Those institutions report LGD in $7.9-25.9 \%$ of cases of Barrett esophagus. Gopal et al. ${ }^{22}$ recently published a prospective multiinstitutional study that attempted to determine risk factors for dysplasia. In that study, LGD was diagnosed in $9.4 \%$ of all Barrett esophagus cases. Although the study conducted by Gopal et al. was multiinstitutional, $75 \%$ of all cases were diagnosed at a Veterans Administration hospital, and thus the study population is not likely to have been representative of the population of individuals with Barrett esophagus in the United States. Most of the reported case series are from surveillance programs, which can best determine the number of incident (newly diagnosed) cases of dysplasia. However, identification of all cases by review of pathology records mimics clinical trial recruitment and provides a better measure of prevalent cases and potential participants available for chemopreventive interventions. The current analysis, in which cases were identified by pathology review, involves an unselected cohort of cases of LGD in Barrett esophagus diagnosed at three institutions serving diverse populations.

The variability across studies is primarily a reflection of problems with the diagnosis of dysplasia. Despite attempts at establishing criteria for the diagnosis of dysplasia in Barrett esophagus in $1988^{27}$ and attempts at refinement of those criteria in $2001,{ }^{28}$ confirmation of the diagnosis remains a significant challenge. Several studies have reported that LGD was not confirmed in approximately $75 \%$ of patients. ${ }^{20,21,23}$ Even among experienced pathologists, the interobserver agreement for the diagnosis of LGD is only $50 \% .{ }^{27,28}$ In the current study, more than three pathologists across the three institutions were involved in reporting LGD. However, results from our recent multiinstitutional clinical trial, in which a central pathologist reviewed all cases, were consistent with the results of the current analysis (2.6\% LGD; unpublished data). Combining the indefinite for dysplasia and LGD categories improves the concordance among pathologists. As a result, some have chosen to combine these diagnoses when reporting rates. ${ }^{13,24,27}$ In the current study, the combined percentage of indefinite/LGD cases was $10.6 \%$. Diagnostic problems will be lessened 
by the further development of biomarkers that can better predict which individuals will experience progression to invasive malignancy ${ }^{29-31}$ However, until that time, difficulties with the pathologic diagnosis will continue to represent a challenge in chemoprevention studies.

Variations in environmental influences and risk groups of Barrett esophagus across the country might also result in differences in the rates of dysplasia that are reported. Limited information is provided in other studies with regard to population characteristics. However, variation in esophageal adenocarcinoma incidence across the country supports the likelihood of regional variation in the occurrence of dysplasia. ${ }^{32}$ In addition, although the columnar epithelium of Barrett mucosa can have a distinctive red hue and velvety texture, dysplasia has no obvious appearance. Thus, sampling error is prominent due to the requirement of random biopsies in standard endoscopic procedures. ${ }^{33}$ Sampling error and spontaneous regression are likely contributors to the difficulty of confirming the diagnosis of LGD in surveillance series. ${ }^{20,21,23}$ More rigorous biopsy techniques, as used for HGD surveillance, ${ }^{14,33}$ may lead to more accurate measures of LGD prevalence, but currently, these techniques are not used routinely for Barrett esophagus or LGD surveillance.

In the current analysis, we used the most advanced diagnosis for each individual. Four cases of LGD were not counted because their diagnoses preceded more advanced diagnoses (i.e., HGD or malignant disease). Consequently, the number of LGD cases may have been underestimated to a small degree. Referral bias is a major concern in reporting prevalence estimates in Barrett esophagus, particularly at large tertiary medical centers. Exclusion of patients referred from extramural physicians for pathologic review limited referral bias, resulting in a more accurate reflection of the number of individuals with dysplasia who would be treated at each institution. Surgical specimens also were excluded, because many patients who undergo surgery represent referral cases. These individuals would also not be available for chemopreventive interventions. However, many individuals with diagnoses of LGD or indefinite for dysplasia undergo follow-up with community gastroenterologists. Therefore, the rates reported from tertiary care centers might not reflect the true prevalence of dysplasia within a given population.

Poor recruitment rates in chemoprevention trials underscore the importance of accurately determining the number of potential participants. The ratio of potential participants screened for enrollment to those who are actually enrolled varies markedly, ranging from $7: 1$ to $>100: 1{ }^{17,34}$ Our recent randomized efficacy trial for a putative chemoprevention agent (i.e., DFMO) required 76 participants per arm to detect a designed morphologic regression or biomarker modulation. ${ }^{17}$ With a screened-to-on-study ratio of 15:1, as encountered in this study, ${ }^{17} 2280$ (i.e., $15 \times 152$ ) otherwise eligible participants would be required. Our intent in performing the current analysis was to determine the recruitment cohort size necessary to study the efficacy of a chemopreventive intervention in a randomized design. Due to the documented low rate of LGD and the poor screened-to-on-study ratio, the screening of such a population would require the collaboration of the bulk of the institutions in the United States to successfully identify, recruit, and retain the necessary number of study participants.

We believe that the current analysis estimates the number of individuals with LGD in Barrett esophagus who are available for chemoprevention studies more accurately than do previous reports. Based on our findings, alternative clinical trial designs will be required to effectively study chemopreventive interventions for patients with Barrett esophagus.

\section{REFERENCES}

1. Spechler SJ, Zeroogian JM, Antonioli DA, Wang HH, Goyal RK. Prevalence of metaplasia at the gastro-oesophageal junction. Lancet. 1994;344:1533-1536.

2. Cameron AJ. Epidemiology of columnar-lined esophagus and adenocarcinoma. Gastroenterol Clin North Am. 1997;26: 487-494.

3. Cameron AJ, Lomboy CT, Pera M, Carpenter HA. Adenocarcinoma of the esophagogastric junction and Barrett's esophagus. Gastroenterology. 1995;109:1541-1546.

4. Haggitt RC, Tryzelaar J, Ellis FH, Colcher H. Adenocarcinoma complicating columnar epithelium-lined (Barrett's) esophagus. Am J Clin Pathol. 1978;70:1-5.

5. Devesa SS, Blot WJ, Fraumeni JF Jr. Changing patterns in the incidence of esophageal and gastric carcinoma in the United States. Cancer. 1998;83:2049-2053.

6. Bozymski EM, Shaheen NJ. Barrett's esophagus: acid suppression, but no regression. Am J Gastroenterol. 1997;92: 556-558.

7. Sampliner RE. Practice guidelines on the diagnosis, surveillance, and therapy of Barrett's esophagus. The practice parameters committee of the American College of Gastroenterology. Am J Gastroenterol. 1998;93:1028-1032.

8. Berenson MM, Johnson TD, Markowitz NR, Buchi KN, Samowitz WS. Restoration of squamous mucosa after ablation of Barrett's esophageal epithelium. Gastroenterology. 1993;104:1686-1691.

9. Sontag SJ. Preventing death of Barrett's cancer: does frequent surveillance endoscopy do it? Am J Med. 2001;111 Suppl 8A:137S-141S.

10. O'Shaughnessy JA, Kelloff GJ, Gordon GB, et al. Treatment and prevention of intraepithelial neoplasia: an important target for accelerated new agent development. Clin Cancer Res. 2002;8:314-346. 
11. Pera M, Trastek VF, Carpenter HA, Allen MS, Deschamps C, Pairolero PC. Barrett's esophagus with high-grade dysplasia: an indication for esophagectomy? Ann Thorac Surg. 1992; 54:199-204.

12. Heitmiller RF, Redmond M, Hamilton SR. Barrett's esophagus with high-grade dysplasia. An indication for prophylactic esophagectomy. Ann Surg. 1996;224:66-71.

13. Hameeteman W, Tytgat GN, Houthoff HJ, van den Tweel JG. Barrett's esophagus: development of dysplasia and adenocarcinoma. Gastroenterology. 1989;96:1249-1256.

14. Levine DS, Haggitt RC, Blount PL, Rabinovitch PS, Rusch VW, Reid BJ. An endoscopic biopsy protocol can differentiate high-grade dysplasia from early adenocarcinoma in Barrett's esophagus. Gastroenterology. 1993;105:40-50.

15. Skacel M, Petras RE, Gramlich TL, Sigel JE, Richter JE, Goldblum JR. The diagnosis of low-grade dysplasia in Barrett's esophagus and its implications for disease progression. Am J Gastroenterol. 2000;95:3383-3387.

16. Weston AP, Banerjee SK, Sharma P, Tran TM, Richards R, Cherian R. p53 protein overexpression in low grade dysplasia (LGD) in Barrett's esophagus: immunohistochemical marker predictive of progression. Am J Gastroenterol. 2001; 96:1355-1362.

17. Brenner DE, Normolle DP, Kresty LA, et al. Effect of difluoromethylornithine upon polyamine content in human metaplastic Barrett's esophagus mucosa [abstract]. Proc Am Assoc Cancer Res. 2002;43:1146.

18. Schnell TG, Sontag SJ, Chejfec G, et al. Long-term nonsurgical management of Barrett's esophagus with high-grade dysplasia. Gastroenterology. 2001;120:1607-1619.

19. Hirota WK, Loughney TM, Lazas DJ, Maydonovitch CL, Rholl V, Wong RK. Specialized intestinal metaplasia, dysplasia, and cancer of the esophagus and esophagogastric junction: prevalence and clinical data. Gastroenterology. 1999; 116:277-285.

20. Weston AP, Krmpotich PT, Cherian R, Dixon A, Topalosvki M. Prospective long-term endoscopic and histological follow-up of short segment Barrett's esophagus: comparison with traditional long segment Barrett's esophagus. Am J Gastroenterol. 1997;92:407-413.

21. O'Connor JB, Falk GW, Richter JE. The incidence of adenocarcinoma and dysplasia in Barrett's esophagus: report on the Cleveland Clinic Barrett's esophagus Registry. Am J Gastroenterol. 1999;94:2037-2042.

22. Gopal DV, Lieberman DA, Magaret N, et al. Risk factors for dysplasia in patients with Barrett's esophagus (BE): results from a multicenter consortium. Dig Dis Sci. 2003;48:15371541.
23. Conio M, Blanchi S, Lapertosa G, et al. Long-term endoscopic surveillance of patients with Barrett's esophagus. Incidence of dysplasia and adenocarcinoma: a prospective study. Am J Gastroenterol. 2003;98:1931-1939.

24. Miros M, Kerlin P, Walker N. Only patients with dysplasia progress to adenocarcinoma in Barrett's oesophagus. Gut. 1991;32:1441-1446.

25. Reid BJ, Levine DS, Longton G, Blount PL, Rabinovitch PS. Predictors of progression to cancer in Barrett's esophagus: baseline histology and flow cytometry identify low- and high-risk patient subsets. Am J Gastroenterol. 2000;95:16691676.

26. McKenna BJ, Appelman HD. Barrett's esophagus: morphologic considerations. In: Heitmiller R, editor. Shackelford's surgery of the alimentary tract (5th edition). Volume I. Philadelphia: WB Saunders, 2002:247-262.

27. Reid BJ, Haggitt RC, Rubin CE, et al. Observer variation in the diagnosis of dysplasia in Barrett's esophagus. Hum Pathol. 1988;19:166-178.

28. Montgomery E, Bronner MP, Goldblum JR, et al. Reproducibility of the diagnosis of dysplasia in Barrett esophagus: a reaffirmation. Hum Pathol. 2001;32:368-378.

29. Reid BJ, Blount PL, Rubin CE, Levine DS, Haggitt RC, Rabinovitch PS. Flow-cytometric and histological progression to malignancy in Barrett's esophagus: prospective endoscopic surveillance of a cohort. Gastroenterology. 1992;102: 1212-1219.

30. Reid BJ, Prevo LJ, Galipeau PC, et al. Predictors of progression in Barrett's esophagus II: baseline 17p (p53) loss of heterozygosity identifies a patient subset at increased risk for neoplastic progression. Am J Gastroenterol. 2001;96: 2839-2848.

31. Regalado SP, Nambu Y, Iannettoni MD, Orringer MB, Beer DG. Abundant expression of the intestinal protein villin in Barrett's metaplasia and esophageal adenocarcinomas. Mol Carcinog. 1998;22:182-189.

32. Ries LA, Kosary CL, Hankey BF, Miller BA, Harras A, Edwards BK. SEER cancer statistics review, 1973-1994. Bethesda: National Cancer Instititute, 1997.

33. Reid BJ, Blount PL, Feng Z, Levine DS. Optimizing endoscopic biopsy detection of early cancers in Barrett's highgrade dysplasia. Am J Gastroenterol. 2000;95:3089-3096.

34. Goodman GE, Valanis B, Meyskens FL Jr., et al. Strategies for recruitment to a population-based lung cancer prevention trial: the CARET experience with heavy smokers. Beta-carotene and retinol efficacy trial. Cancer Epidemiol Biomarkers Prev. 1998;7:405-412. 